\title{
Language Abilities of 18-month-old Zulu Speakers
}

\author{
Melissa A. Bortz \\ Department of Speech Pathology and Audiology \\ University of the Witwatersrand
}

\begin{abstract}
The receptive, expressive and pragmatic language abilities of 18-month-old Zulu speakers were assessed in order to obtain preliminary norms. Twenty-five participants of the Birth to Ten cohort study were investigated using parent reports, mother-child and tester-child interactions. Data was transcribed and analysed using nonparametric statistics. Results demonstrated that receptively subjects understood two-part instructions. Expressively, the mean lexicon was 4.12 words and mean length of utterance 0.65. Pragmatically, subjects were functioning on a nonverbal level and exhibited culture-specific items. The results provided information which could enable speech, language and hearing therapists to engage in primary and secondary prevention. An appropriate test battery for these children is discussed.
\end{abstract}

\section{OPSOMMING}

Die respetiewe, ekspresiewe en pragmatiese taalvermoëns van 18 maande oue Zulusprekers is geëvalueer om voorlopige norms op te stel. Vyf en twintig deelnemers aan die Geboorte tot Tien longtudinale studie is deur middel van oueronderhoude, moeder-kind-en toetserkindinteraksies ondersoek. Data is getranskribeer en geanaliseer deur middel van nonparametiese statestiek. Die resultate dui aan dat die' proefpersone op reseptiewe vlak instruksies bestaande uit twee komponente, begryp het. Op ekspressiewe vlak was die gemiddelde leksikon 4.12 woorde en die gemiddelde lengte van 'n uiting 0.65 . Op pragmatiese vlak het die proefpersone op 'n nie-verbale vlak funksioneer en kultuurspesifike gedrag vertoon. Die resultate het inligting verskaf wat spraak-taal-en-gehoorterapeute in staat kan stel om betrokke te raak in primêre en sekondêre voorkoming van taalprobleme. 'n Geskikte toetsbattery vir hierdie kinders is bespreek.

Epidemiology is the professional discipline concerned with "searching out and understaniding the factors relating to the occurrence of disease in the population" (Peterson \& Thomas, 1978 , p. xv). Mausner and Bahn (1985) cited by M. Marge ${ }^{\star 1}$ (personal communication, April 20, 1992), have defined epidemiology as the study of the distribution and determinants of disorders in human populations. A cohort study is based upon one of the methods used by epidemiologists to study disease occurrence and has been described as "a systematic follow up of a group of people for a defined period of time" (The Oxford Reference Concise Medical Dictionary, 1990 p. 142). Cohen and Manion (1991) have described cohort studies as prospective longitudinal methods which "are particularly appropriate in research on human growth and development" (p. 73). Cohorts usually refer to a birth cohort which contain persons born in a specified period of time (Miller \& Keane, 1983).

Although cohort studies belong to the realm of epidemiology, they are also a powerful tool that can be used for descriptive research, which is concerned with "acquisition of skills in young children" (Cohen \& Manion, 1991, p. 70). This methodology has been adopted by speech, language and hearing therapists who have made use of cohorts for developmental research, such as the Connecticut Longitudinal Study in which mother-infant communication was examined('lhoman, 1981,

\footnotetext{
*' M. Marge (1992) Professor communication sciences and disorders, Division of special education and rehabilitation. Syracuse University.
}

p. 194). Epidemiology, from a speech, language and hearing therapists' perspective, is concerned with the prevention of communicative disorders, where prevention usually occurs at three levels: primary, secondary and tertiary (Gerber, 1990). Primary prevention refers to the elimination of the occurrence of a communicative disorder, for example, by mass public education and the promotion of better health in general; secondary prevention focuses on early detection and treatment of a communication problem and tertiary prevention relates to rehabilitation, the traditional focus of attention for speech, language and hearing therapists (Gerber, 1990; Marge, 1991).

Marge (1984, cited in Gerber, 1990, p. 319) has contended that "preventing communicative disorders should be the added new dimension to the professional responsibility of speech-language pathologists and audiologists". According to Van Haatum (1980, cited in Gerber, 1990) this "will ultimately prove to be more productive than curing" ( $p$. xiii). 'l'his has been reiterated by Segal who quoted Critical Health, (1982,pp. 12-13) when motivating for a re-allocation of priorities: to direct more effort to prevention than cure. Furthermore Child and Johnson (1992, p. 1) have declared "an ounce of prevention" may truly be worth "a pound of cure". 'The committee on Prevention of Speech-Language and Hearing problems of ASHA (1983) referred to in Gerber (p. 311) strongly recommended that increased development, and implementation of primary prevention strategies should be undertaken. particularly for low-income populations, who are at the greatest 
risk for conditions that can lead to communication disorders. Once early identification and screening for communication problems have taken place, it is possible to determine the incidence and prevalence of speech problems.

In South Africa, speech, language and hearing therapists have not concentrated their efforts on prevention of communication disorders, particularly for the "vast sections of the population who do not receive even the most basic speech therapy" (Drew, 1982). A possible explanation for this is that we have limited tools available to perform the identification of speech and language problems, and those that do exist are inadequate (Ballantine, Ballantine \& Morgan, 1982).

The writer, a speech, language and hearing therapist, was given the opportunity, to enter the field of epidemiology and prevention by participating in a cohort study entitled Birth to Ten: Children of the Nineties, which is currently in operation on the Witwatersrand. This is a ten year longitudinal study, combining over thirty different disciplines studying the growth and child health development of children born between April and June 1990, in Johannesburg and Soweto. The speech and language project of Birth to Ten, is aimed at collecting information on the acquisition of speech and language in the targeted children, of various language groups prevalent in this area, with a view to establishing normative data. An additional aim of the study is to develop, modify and standardise measurement tools and procedures for assessing speech and language development. The purpose of this particular substudy was twofold: 1) to investigate the language abilities of 18-month-old Zulu speakers with a view to establishing preliminary norms, and 2) to evaluate the effectiveness of the assessment materials utilised in the study. The establishment of such preliminary norms has "definite implications for secondary prevention, that is mass screening and early identification once the norms have been established" (M. Marge, personal communication, April 20,1992). It is necessary to study early language development so that timeous identification of language problems can be performed. This can prevent the broad and long term effects of language disorders in children, such as the "extreme emotional side effects of being learning disabled" (Vorster, 1980, p. 2).

The definitions of language and its components used in this study are as follows: Language "is a code whereby ideas about the world are represented through a conventional system of arbitrary signals for communication" (Lahey, 1988, p. 2). The components of language are receptive language, which is defined by Nicolosi, Harryman \& Kresheck $(1989$, p. 142) as "spoken messages received by the individual"; expressive language or the "use of conventional symbols to communicate one's perceptions, ideas, feelings or intentions to others" (Nicolosi et al., 1989, p. 141); and pragmatics or use which is defined by Bernstein \& Tiegerman (1989) as the rules relating to the use of language in social contexts. Both the verbal and nonverbal a spects of pragmatics were considered and morphology, syntax and semantics were regarded both receptively and expressively. All these components are interrelated and interact dynamically in communication.

Bernstein \& Tiegerman (1989) have contended that from a developmental perspective, communication precedes and facilitates speech and language behaviour while both semantics

1 The term toddler is used as an equivalent form of 18 -month-old in this study.

2 Zulu was spoken by 6,5 million people in 1980 according to the Central Statistical Service. This is the most recent figure available. A new figure will only be available in late 1992 when the results of the 1991 census are published. and syntactic functions are derived from pragmatic experien. ces. From birth to 24 months children use different forms of behaviour such as vocal, gestural and lexical, to signal interaction or to produce speech acts, all of which occur in the social context. Between 12 and 24 months children first acquire phonemes followed by lexical items based upon the emerging phonological and semantic systems (Bemstein \& Tiegerman, 1989).

18-month-old children or toddlers' can either be at the illocutionary stage of communication development, in that they use symbolic means to convey intentions, or at the locutionary phase in which they use language to express meaning (Bates, Camioni \& Volterra, 1979; Ochs \& Schieffelin, 1979). Gesell (1954) maintained that 18-month-old children communicate by both gesture and words and, that in fact, words can be accompanied by gestures or even begin replacing these. The child may have a vocabulary of ten words and may be egocentric at this stage but it can be seen that she/he is beginning to communicate more than younger children. The 18 -month-old plays independently but will react to companions. Nicolosi \& Collins (1989) have claimed that 18 -month-olds understand simple commands and prohibitions, recognise familiar objects and persons and identify one body part. Expressively, they have an average sentence length of 1.5 words and say two or three word combinations.

It was mentioned previously that the purpose of this study was to examine the language abilities of Zulu speakers. The reason for this is that Zulu is the most commonly spoken African language in South Africa ${ }^{2}$. Although it is the language primarily of Natal and KwaZulu, Suzman (1990) has maintained that it is also the lingua franca of cities in the Transvaal.

\section{Linguistic Features of Zulu}

Structurally, Zulu is an agglutinating language in that various morphemes are combined to form a single word, in which simultaneously, each element maintains a distinct and fixed meaning (Fromkin \& Rodman, 1978). It can also be described as a synthetic language in which grammatical relations depend mostly on affixes (Bhatnager \& Whitaker, 1984); and a tonal language where tone has a grammatical function, a lexical function and serves to maintain syllable prominence (Suzman, 1990). Furthermore, Zulu is a SVO language with a reasonably flexible word order (Suzman, 1990). The actual structure of Zulu is characterised by three features: the noun class system, extensive concord and a full suffix system of verbal derivatives (Doke, 1945).

Taking the above mentioned information into account the present study was designed to determine the language abilities of 18 -month-old Zulu speakers by investigating the communication development from which language develops. A further goal was to devise a suitable repertoire of assessment procedures for this sample group.

\section{METHOD}

\section{Subjects}

Twenty-five first language Zulu speakers from the Birth to Ten Cohort Study were selected. Being participants in Birth to Ten implied that all subjects met the following criteria:

- subjects were residents in either Johannesburg or Soweto

- subjects had been enroled in the Birth to' $T$ en from its inception, that is, they had antenatal, six month and one year questionnaires completed. The different disciplines participating in the Birth to T'en had asked pertinent questions at all of these stages which had been compiled into ques- 
tionnaires which were administered by specially trained fieldworkers. Speech and language questions asked, included details about case history factors and biographical information such as languages spoken in the home. In addition, for the purposes of this study all subjects met the criteria described below:

- all subjects resided in Soweto, to ensure homogeneity of environment

- subjects were in the age range $18-20$ months so that they could be expected to be both understanding simple commands and producing a small number of words and possibly joining these together in two word phrases (Hopper \& Naremore, 1978; Nicolosi \& Collins, 1989), thus providing sufficient communication behaviour to evaluate

- subjects were first language Zulu speakers as reported by their parents in the Birth to Ten questionnaires

- 13 male and 12 female subjects were selected in an attempt to eliminate the effects of the sex variable

- all subjects were accompanied to the evaluation by the person who usually took care of the child, either the mother or the caregiver as "bonding with a caregiver... fosters speech development" (Van Riper \& Emerick, 1990, p. 92). ${ }^{3}$

\section{Procedures}

Pretest prepar ation. All appointments for the assessment were made by research assistants who personally visited each subject and the caregiver, in Soweto, in order to explain the purpose of the project and to give explicit directions on how to reach the test venue. These personal contacts proved successful as the response rate for attendance at the test situation was high.

\section{Communication Sampling Procedures}

1. Parent report measure. According to Dale (1991) parent report can provide valuable information on early child language development particularly in the age range $8-30$ months. Prior to the formal assessment research assistants asked mothers specific questions about the communication behaviours that their children were using. The parent report was devised by the writer based on information on development of child language from sources such as Nicolosi \& Collins (1989); Gesell (1954) and Hopper \& Naremore (1978). (See

3 The term mother and caregiver will be used interchangeably.
Appendix A).

2. Language sampling. A 40 minute sample of each subject's communicative behaviour was obtained, consisting of a 20 minute mother-child interaction, in which the mother and the child interacted freely, and a 20 minute tester-child interaction in which the clinician gave a variety of questions and commands in order to "analyse children's comprehension and expression through answers to questions and responses to commands" (Miller, 1981, p. 13). This sampling procedure was loosely based on that described by Miller (1981), when he suggested that 30 minutes should be used to obtain a language sample, as this is an appropriate length of time for the concentration span of 18-month-old children and that 30 - 60 utterances should be elicited in this period. All samples were recorded on a National VHS MS2 video camera and audio taped on a Sanyo TRC 2500 tape recorder, for back up. The testing situation took place in a one-way mirror room at the University of the Witwatersrand Speech and Hearing Clinic (USHC).

2.1 Mother-child interaction. The objective of this interaction was to observe the communication between the mother and child. In order to stimulate communication, subjects and their mothers were given objects appropriate to age and culture, from two of the categories identified by Reynolds (1989). Stimuli therefore were either specific play objects eg. dolls and balls or items borrowed from the adult world such as eating utensils and towels. The stimuli were placed in accessible parts of the testing room and the caregivers were instructed to interact with their children as they would at home "in a natural manner" (Wetherby, Yonclas \& Bryan, 1989, p. 151). It is however, acknowledged that mothers may not play with, or speak to children in this way at home.

2.2 Tester-child interaction. Receptive and expressive language was elicited in the tester-child interaction by the child either having to choose or name an item from three familiar objects that is inkomishi 'cup', ibhola 'ball' and indishi 'plate' as for the Reynell Developmental Language Scales (1978): Furthermore, pragmatic behaviour was elicited according to a "standard series of communicative situations" devised by Wetherby and Prutting (1984, p. 151) "to induce child-initiated communicative behaviour". The tester waited and looked expectantly at the child and responded naturally to the child's communicative behaviour. An example was to blow up a balloon, deflate it and then give it to the child and observe the reaction and to react appropriately to it. See Table 1.

Table 1: Communication Sampling Procedures

\begin{tabular}{|l|l|l|l|}
\hline & $\begin{array}{l}\text { Receptive Language } \\
\text { Abilities }\end{array}$ & $\begin{array}{l}\text { Expressive Language } \\
\text { Abilities }\end{array}$ & $\begin{array}{l}\text { Pragmatic Language } \\
\text { Abilities }\end{array}$ \\
\hline Parent Report & $\begin{array}{l}\text { Questions 2, 4, 9 and 10 on } \\
\text { Appendix A, to elicit knowledge } \\
\text { about receptive language }\end{array}$ & $\begin{array}{l}\text { Questions 1,3,5 and 8 on } \\
\text { Appendix A to elicit knowledge } \\
\text { about expressive language }\end{array}$ & $\begin{array}{l}\text { Questions } 6 \text { and } 7 \text { to elicit } \\
\text { knowledge about pragmatics }\end{array}$ \\
\hline $\begin{array}{l}\text { Mother-child } \\
\text { interaction }\end{array}$ & Not tested & $\begin{array}{l}\text { MLU. } \\
\text { Mean number of utterances } \\
\text { per turn. } \\
\text { Topic Shifts }\end{array}$ & $\begin{array}{l}\text { Qualitative assessment of } \\
\text { communicative behaviours }\end{array}$ \\
\hline Tester-child interaction & $\begin{array}{l}\text { Child to identify inkomishi } \\
\text { 'cup', ibhola 'ball' and indishi } \\
\text { 'plate' and body parts } \\
\text { 'cup', ibhola 'ball' and indishi }\end{array}$ & $\begin{array}{l}\text { Child to name inkomishi } \\
\text { 'plate' and body parts }\end{array}$ & $\begin{array}{l}\text { Eliciting pragmatics from } \\
\text { standard series of communica- } \\
\text { tion situations }\end{array}$ \\
\hline
\end{tabular}




\section{Research Assistants}

The study was conducted by four research assistants, diplomates in Speech and Hearing (Community work) and who were fluent in both Zulu and English. They established contact with the mothers, performed the testing and transcribed and scored the data.

\section{Pilot Study}

The aim of the pilot study was to determine the suitability of the procedures and stimuli described above and the length of time it would take to administer such a procedure. The pilot study was performed on seven subjects who met the criteria for the research, previously mentioned. A preliminary version of the research was devised, based on principles of language testing and materials devised for children of this age such as the Reynell Developmental Language Scales (1978). Care was taken to make the procedures relevant and appropriate to the South African population so I consulted with researchers who had previously conducted investigations into Zulu language acquisition such as S. M. Suzman ${ }^{\star 2}$ (personal communication, October, 1991). In addition, preliminary scoring procedures were devised. Results of the pilot study demonstrated that the proposed testing and scoring procedures were appropriate and provided useful information for analysis. Furthermore, the pilot study indicated that the optimal length of time for the mother-child interaction was 20 minutes as children did not provide additional information for language sampling, thereafter. Certain stimuli such as a teddy bear were eliminated as this frightened the subjects.

\section{Analysis of the Communication Sample}

Transcription. In pairs, the research assistants transcribed the mother-child interactions and the contexts in which these occurred, using standard orthography (Miller, 1981; Conti-Ramsden \& Dykins, 1991). Thereafter, pairs of research assistants viewed segments of the video tape, repeatedly, until they established agreement on the interaction. In addition, the transcription was translated from Zulu into English for me to understand what had been said.

Scoring. The following structural analysis was performed on the mother-child interaction.

1. Mean length of utterance (MLU). The MLU for both child and mother was counted in morphemes because Zulu has an "extremely rich morphology" (Suzman, 1990 abstract). MLU was calculated according to Miller's (1981) counting rules. Paralinguistic features were not included and MLU was only counted for fully intelligible utterances. The mean num. ber of morphemes and the mean number of utterances, used to calculate MLU, were judged individually, as these figures provide valuable information. Percentage of clear and unintelligible utterances was also considered individually.

2. Mean number of utterances per turn. The number of utterances for both child and mother were calculated in order to measure the density of each speaker's turn. This was determined by taking the number of utterances for each speaker, and the number of turns for that speaker and dividing them (G.Conti-Ramsden ${ }^{* 3}$, personal communication, April 14, 1992). *2 S.M. Suzman (1991) Phd, Department of Linguistics, University of
the Witwatersrand.

*3 G. Conti-Ramsden (1992), Phd, Centre for educational guidance and special needs, school of special education, University of Manchester.
3. Topic shifts. Topic shifts occur when one of the conversational partners disengages her/himself from the previous set of concerns at either the verbal or nonverbal level (Conti. Ramsden \& Dykins, 1991). These were counted as having occurred when either the mother or the child changed both the focus and the theme of the conversation or the toys they were playing with as suggested by G. Conti-Ramsden (personal communication, April 14, 1992).

4. Parent report and tester child interaction. The parent report and tester-child interaction samples were scored by a pair of research assistants according to a format devised by the writer where responses were analysed as being correct or appropriate, incorrect or inappropriate, or, not tested. The 'not tested' category included any item not examined by the re. search assistants either due to a lack of response by the subjects or the subjects not responding to the previous stimulus eg. on the tester-child interaction if the subject could not point to indishi 'plate' because of loss of attention, then the next item, inkomishi 'cup', was not tested.

The pragmatic interaction was scored as a communication act when "the child initiated interaction with the adult or focused attention on an object" (Wetherby et al., 1989, p. 151). Wetherby etal. (1989) have described intentional communicative acts that occur as a result of the interaction in detail, but because the subjects only focused attention on objects, and there was little interaction with adults, this was not investigated further.

All scores obtained were converted to percentages and analysed by means of nonparametric statistics. Results will be discussed in terms of these values.

\section{Interrater Reliability}

Research assistants worked in pairs in order to transcribe and score the full data sets. The, $30 \%$ of the data were randomly selected and independently recoded as suggested by ContiRamsden \& Dykins (1991). Interrater reliability was calculated according to the following formula proposed by McReynolds \& Kearns, (1983):

Percentage agreement $=\longrightarrow$ Agreements $=100$ Agreements \& Disagreements

Attempts were made to achieve a minimum of $80 \%$ agreement with this formula but only $66 \%$ agreement was obtained. Poor interrater reliability is not uncommon with children this age. Bates, Bretherton and Snyder (1988) attempted to obtain similar agreement with 20 month olds and could not, as subjects of this age have "a relatively high proportion of unintelligible utterances" (p. 84).

\section{RESULTS AND DISCUSSION}

The results from the analyses of communication samples are presented below. They are divided into receptive, expressive and pragmatic language abilities, insofar as it was possible to separate these related skills. Parent report, mother-child interaction and tester-child interaction will be discussed for each section. A discussion of a suitable repertoire of assessment tasks, based on these findings, follows.

\section{Receptive Language Abilities}

Parent report. From parents reports it appears that $95,5 \%$ of the subjects listened, when communication was addressed to them and responded appropriately to this communication, for example, by either looking at or approaching the mother when called, while $4,5 \%$ of the subjects did not respond to communication. Responding to communication is regarded as 
age appropriate according to Nicolosi \& Collins, (1989). All of the children were reported to understand what was being said to them and could follow two-part instructions such as hlalapantsi udle 'sit down and eat' and hamba uyalale 'go and sleep'.

Nicolosi and Collins (1989) have stated that 18-month-old hildren should be able to identify one body part. In this sample $63,6 \%$ of children were reported to be able to do so while $36,4 \%$ could not. Children were able to identify ten different parts of their bodies and most often able to point to their izindlebe 'ears' ( 9 subjects), and least often to their ubuso 'face', iminwe 'finger' or isisu 'stomach' (See Figure 1 for exact information)

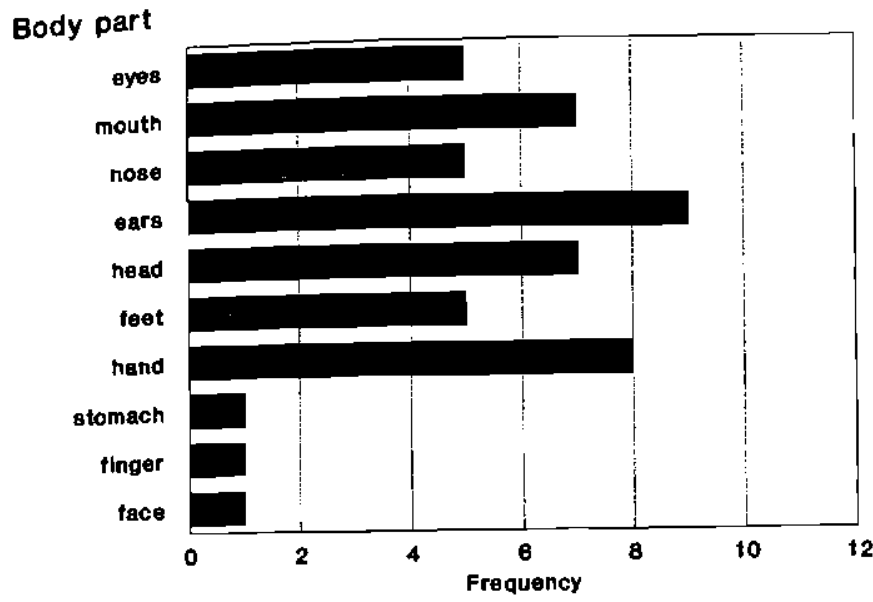

Figure 1: Frequency of correct identification of body parts

Children's ability to identify their body parts was also assessed in the tester-child interaction, in which it was found that ten of the subjects $(40 \%)$ did not respond to this task while nine subjects $(36 \%)$ could identify body parts such as izindlebe 'ears' and umlomo 'mouth' and six subjects ( $24 \%$ ) could not identify parts of their bodies. The subjects' ability to identify body parts appears to be more advanced than their English speaking counterparts. Hedrick, Prather \& Tobin (1984), in their standardisation sample for the Sequenced Inventory of Communication Development, (SICD), found that children were able to point to their eyes, hair, mouth and nose at two years and only at 28 months to their ears, al though certain subjects of this study could identify all the above, including ears, at 18 months. The results obtained in the parent-child report and the tester-child interaction were correlated using a Spearman correlation coefficient resulting in a poor correlation ( $\mathrm{r}=.149)$. Thus, parents maintained that children knew more parts of the body than the testing situation indicated.

Tester-child interaction. The majority of the subjects were able to point to the objects in the tester-child interaction: specifically $72 \%$ ( 18 subjects) were able to identify inkomishi 'cup', $80 \%$ (20 subjects) could recognise ibhola 'ball' and $60 \%$ (15 subjects) identified indishi 'plate' (See Figure 2). It is interesting to note that fewer subjects were able to identify the objects as the procedure continued, while the percentage of children who could not be tested increased from $16 \%$ for the identification of inkomishi 'cup' to $40 \%$ at the end of the procedure, possibly signifying that the subjects were losing concentration towards the end of this task.

To summarise the findings about receptive language abili-

4 It should be noted that the reliability of parent report was not formally assessed. This is seen as a limitation of this study.

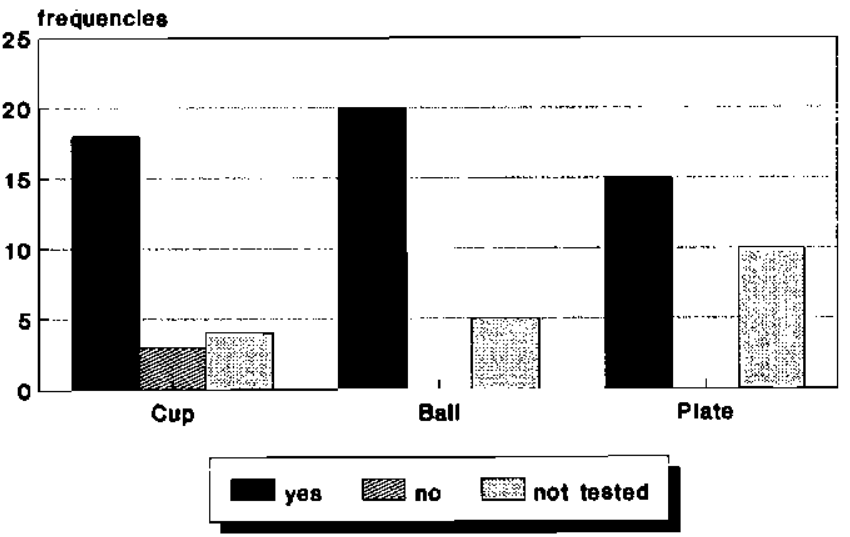

Figure 2: Frequency for tester-child receptive abilities

ties, it was found that $54 \%$ of children understood the questions, while $26 \%$ could not be tested in this way and $18 \%$ did not understand the instructions. Therefore, the majority of children in the study were understanding symbolic representation and as such, relating words to toys (Reynell, 1977). As regards the most suitable repertoire of assessment procedures to use for reception, the parent report appeared to yield more information than when the tester assessed the child, as it was difficult to obtain cooperation from children this young ${ }^{4}$. This confirms the findings of Dale (1991) who maintained that parent report "is more representative of toddler language than laboratory samples" (p. 566).

\section{Expressive Language Abilities}

Parent report. Nicolosi \& Collins (1989) have contended that jargon is at its peak at 18 months and Gesell (1954) has reported that children of this age conduct expressive inflected "conversation" (p. 32 ). All subjects $(100 \%)$ were reported to babble and use jargon. Parents reported believing this to be appropriate in $74 \%$ of cases and inappropriate in $26 \%$ of instances. Twenty-four subjects were reported as using imitation and all of the subjects were reported as able to sing, which is common in the expressive abilities of children this age. All mothers reported that their children were saying words. The subjects' words reported by the mothers are presented in Figure 3. According to Clark $(1979$, p. 160) the first words children say "show considerable agreement... across children and across languages". These first words refer to "here and now" topics and fall into the following categories: people, particularly "adult caretakers familiar to the child" food, house-

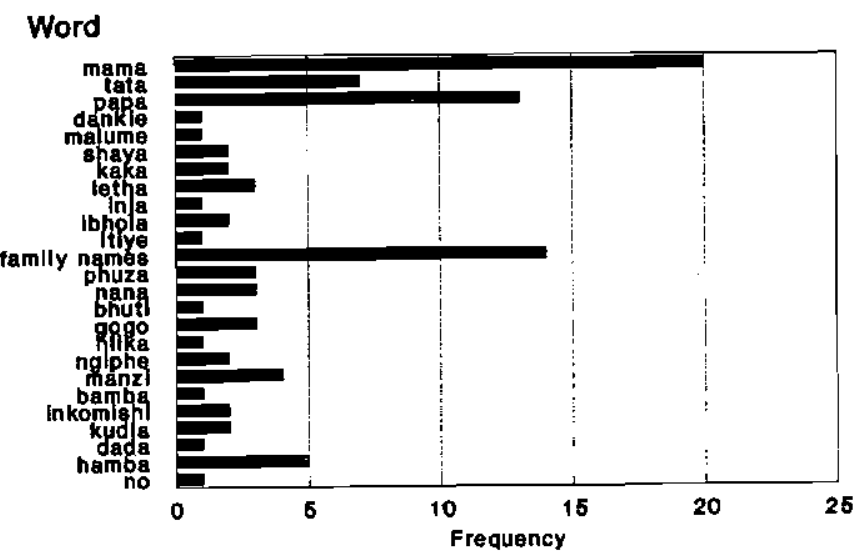

Figure 3: Words children are saying according to caregivers 
hold items like cup, toys like ball, body parts and actions. It can be seen that the words the subjects were saying concur with these categories for example inkomishi 'cup', for household items. The mean lexicon of each child was 4,12 words, with a standard deviation of 2,2 words, and a pool of 25 words. Dale $(1990$, p. 566) has asserted that parent report is "potentially an excellent measure of vocabulary development" and therefore these results could be regarded as providing information concerning a preliminary lexicon for these children, although it is acknowledged that for a truly representative lexicon a larger sample of children would have to be tested.

The literature describes a broad range in the number of words that children are expected to produce at 18 months. This mostly depends on the source and particular discipline that is being referred to, as paediatricians tend to expect children to produce small numbers of words, for example Illingworth (1983), has reported that children can name a single word at 18 months and Holt $(1977$, p. 218) suggested that paediatricians should only be alerted to further investigation for an expressive language problem if "a child of 18 months" is not "producing at least one or two words". Linguists and language therapists expect toddlers to be saying many more words at this stage, for example Nicolosi \& Collins (1989) have noted that 18 -month-olds produce $10-20$ words while Clark (1979) has stated that toddlers should have lexicons of approximately 50 words.

It is interesting to note that, of the words the children were saying, several are not pure Zulu forms but adoptives from other languages such as bhuti 'brother' and dankie 'thankyou' from Afrikaans or no, from English. This is a common feature of the Zulu that people on the Witwatersrand speak. (M. Mngadi*4, personal communication, July 20,1992).

In this sample, morphology was not formally assessed, but it was noted that some children used marked forms of the word and correctly denoted which noun classes the words belonged to, such as ibhola 'ball', noun class 5 and amanzi 'water', noun class 6 and others used the unmarked form manzi. ( $M$. Mngadi, personal communication, July 20,1992). This use of the prefix in Zulu could be compared to English speakers' beginning to put two or three words together which is a normal development at this stage (Hopper \& Naremore, 1978; Nicolosi \& Collins, 1989). A more detailed investigation of morphology and syntax will be undertaken in a separate study in the Birth to Ten cohort programme.

Mother-child interaction. Complexity measures of syntax revealed that the subjects had an MLU of 0,38 which is below the mean of 1,14 and 1,31, that English speaking children are reported as having at this stage (Miller, 1981 p. 27; Bates et al., 1988, p.85). Miller (1981, p. 25) has cautioned that "MLU can only be interpreted when the criteria for representativeness of the speech sample, such as sample size, have been satisfied". Bates et al.,(1988) have contended that to calculate MLU "a traditional minimum of fifty intelligible utterances" is required (p. 85). In the study of Bates et al., (1988) investigating the MLU of 20 month olds, a MLU score of 1,00 was assigned to the children who produced only single-word utterances when "the number of intelligible utterances fell well below this criterion" (p. 85). Even when using the same adjustments instituted by Bates et al., (1988) for the ten subjects of this study whose number of utterances was below 50 , the MLU for this sample remained below that of English speaking subjects, at 0,65. This MLU, however, indicates that the sub-

\footnotetext{
*4. Mngadi (1992), Senior tutor, Department of African Languages,
University of the Witwatersrand.
}

jects were functioning at the "early one-word stage" or "sensorimotor stage $V$ " which is acceptable in the age range $10-18$ months (Miller, 1981, p. 55).

Bates et al. (1988) also found their subjects to have a range of MLUs of from 1,00 to 2,1 1. Similar fluctuations were found in this study, with one subject not saying anything and another having a MLU of 1 word. It was found, however, that the child ren were using an average of 2,78 different morphemes in this interaction. The mean number of utterances produced was 72,4 with a large discrepancy between three in one child and 202 in another

The mean number of clear utterances for the sample was 1,17 , while the mean number of unintelligible utterances was 0,74 , indicating that although subjects was saying few utterances, most of those that were produced, were in telligible. It must be remembered, that, according to the rules for counting morphemes in each utterance, fillers such as 'aaaa' were not counted (Miller, 1981,p. 24). These constituted a large portion of what the children were saying, as they were at the jargon stage of production (Gesell, 1954).

Chapman, (1981, p. 206) has noted that "mothers speech averages about 2,4 morphemes longer than her child's during the 12-27 month period". Results of the current study are not consistent with this finding, as mothers' MLU was approximately one morpheme longer than their childrens' (mothers MLU 1,4 and children's 0,65). A possible explanation for this is that mothers' MLU varies with conversational context and is shortest in free play situations, from which this sample was elicited (Snow, 1972, cited in Chapman, 1981, p. 206). The MLU for both mothers and children was more restricted in this sample, than the MLU reported in the literature for English speaking subjects. A Pearson Correlation Coefficient indicated a poor correlation ( $r=.21$ ) suggesting that the mothers' speech did not affect the childrens' speech (see Figure 4). The mean number of utterances per turn for the children was 1,519 and for mothers, was 3,32 , showing that mothers were saying more in each turn, than their children, which is to be expected given the superior language skills that adults have. There was a poor correlation between the mothers' speech and that of their children ( $r=.33$ ). Furthermore the subjects changed the topic more often than the caregivers with a mean number of 22 times and the caregivers with a mean of 18 times. This could suggest that subjects were concentrating on the conversation or toys that they were playing with, for short periods of time, which is to be expected at this age.

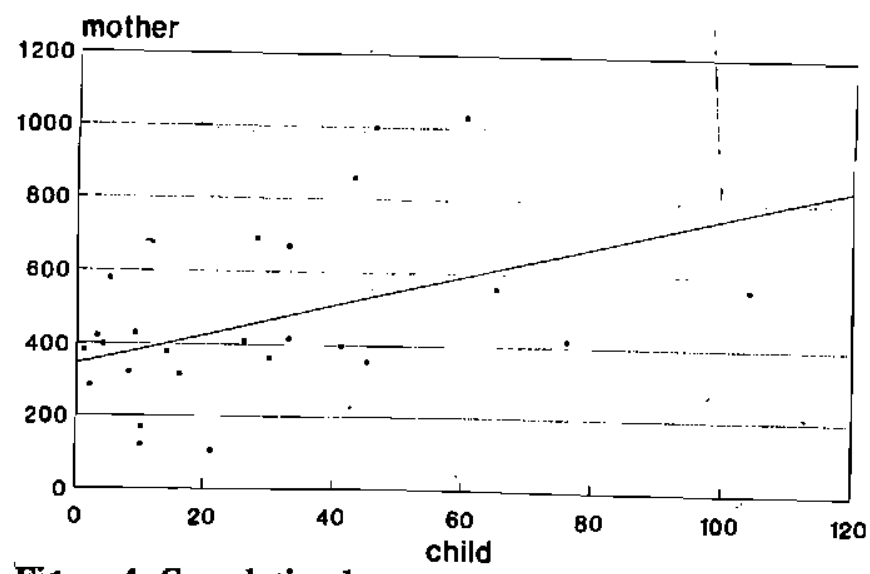

Figure 4: Correlation between number of morphemes of mother and child

Tester-child interaction. The majority of subjects were not able to name items that they had identified in the receptive tasks, providing no response to items, so earning a "not tested" 
classification. On the item indishi 'plate' three of the subjects roduce the name (12\%); one subject was able to name inkomishi 'cup', and only four subjects ( $16 \%$ ) were able to inkomishi 'cup', and only four subjects ( $16 \%$ ) were able to name ibhola 'ball'. None of the children was able to name body parts. (See Figure 5.)

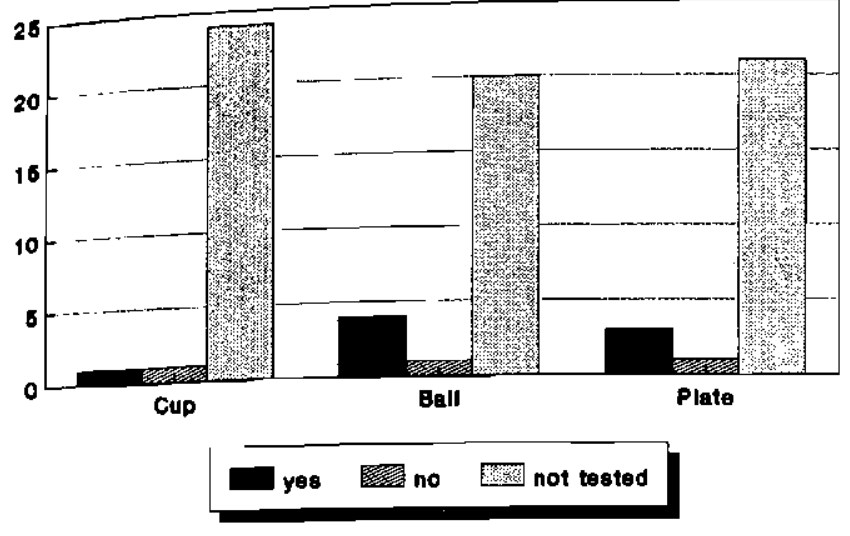

Figure 5: Frequencies for tester-child expressive abilities

From these results, it can be seen that the tester-child assessment of expression yielded very few examples of childrens' ability to name objects. These data indicating poor naming capabilities support the findings of the limited expressive abilities of these subjects on the mother-child interaction sampling. Although the subjects exhibited restricted MLUs in the mother-child test situation, their MLUs $(0,65)$ however, did indicate an ability express themselves. These poor results therefore do not reflect an inability to verbalise, but, suggest the unsuitability of the task, for these children.

The fact that the subjects' expression seems to be more limited than their reception is not unexpected, as it is well documented that the development of receptive language precedes expression. Results of the tests of expression for these subjects did, however, indicate that their expressive language abilities were more limited than those reported in studies performed on certain of their English speaking peers, as can be seen from the few words they are producing and their restricted MLU.

\section{Pragmatic Language Abilities}

Parent report. All the subjects were able to communicate their needs and $95,5 \%$ were able to do so appropriately. Appropriate responses included saying mama or papa while pointing to the required object. Inappropriate responses were those in which the parents did not understand the child's communication eg. in non specific crying. All children were also reported to be using gesture to communicate intention.

Mother-child interaction. An ethnographic approach as defined by McTear and Conti-Ramsden (1992) was taken for this analysis, where the emphasis was on qualitative, rather than on quantitative analysis eg. a description of all communicative behaviours was therefore recorded. The absence of evidence of a communicative behaviour however can not be construed as implying absence from a child's repertoire (Roth \& Spekman, 1984). Forty-four percent of the children attempted to sweep with a broom while $56 \%$ of subjects did not exhibit this behaviour. According to Illingsworth (1983) who has commented that toddlers "copy mother in her domestic work for example sweeping the floor" (p. 145), this activity is typical. Thirteen of the subjects were observed to carry dolls tied to their backs, after the mothers had put them there. This is strongly related to how mothers traditionally carry their children (Read, 1959). The above two activities are indicative of Halliday's account of pretend play which is part of the imaginative act of Phase I language functions and which occurred in her child at 18 months showing that these children are functioning in a similar way to their English speaking peers (Halliday, 1975, cited in Miller, 1981). In addition, subjects were observed engaging in autosymbolic play such as brushing their teeth with a toothbrush. They also used common objects and toys appropriately, such as playing with a car or ball. Due to the qualitative nature of the analysis utilised for the spontaneous emergence of communicative behaviour, exact scores were not obtained but their presence demonstrates that the subjects were functioning at Stage III of Westby's Symbolic Play Scale Check List, which occurs between 17 and 19 months (Westby, 1980). It must be stressed however that non emergence of a behaviour was in no way interpreted as absence from the child's repertoire.

Researcher-child interaction. The results of the analysis of subjects' responses to the standard series of communication situations (Wetherby \& Prutting 1984) are presented in Figure 6. It can be seen that subjects responded positively to communication acts by focusing attention on them.

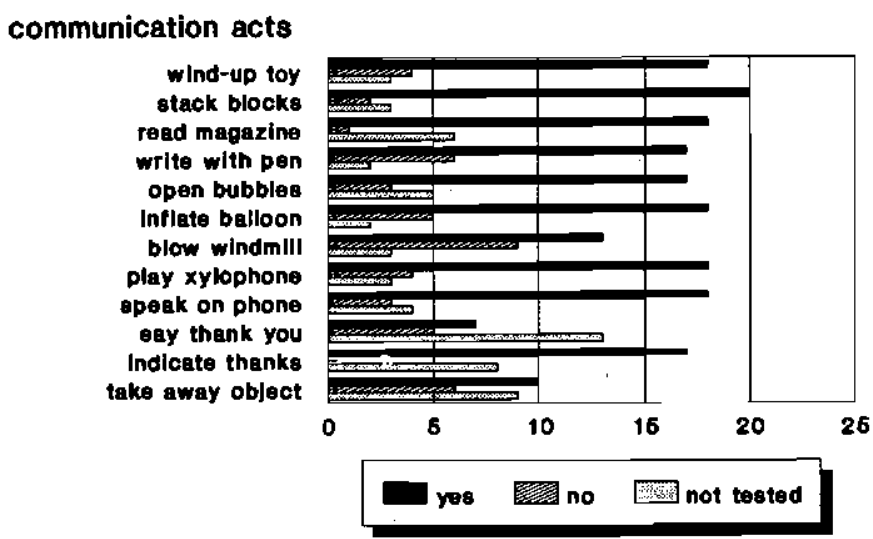

Figure 6: Frequencies for tester-child pragmatic abilities

Saying thank you had more responses of not tested than positive responses: $52 \%$ of subjects were not tested on this item while $32 \%$ were able to thank. These results could be attributed to the fact that these targets could not be elicited in this way, as the subjects did not appear to be able to understand the verbal command to thank the tester. However, subjects were able to indicate thanks when they imitated their mothers doing so. The subjects' improved ability to indicate thanks could be culture specific as the thanking ritual is indicative of Zulu culture where the subject is instructed papate 'thank' and then claps her/his hands before receiving something (Gowlett, 1975, p. 14).

The responses to the communicative acts were more often manifest by the child's focusing of attention on the object than by his/her interacting with the adult. According to Wetherby et al., (1989), this is appropriate albeit on a nonverbal level. Some vocalisation did occur and accompany gesture, for example during telephone play. The fact that children primarily responded to communication acts nonverbally corresponds with the limited level of the childrens expressive repertoire, previously discussed. This further demonstrates the related and integrated nature of the acquisition of language abilities. Another possible reason for responses being mainly nonverbal could be attributed to the highly structured nature of the 
task which did not, in fact, pragmatically, require a verbal response from the children: for example, there was no need to request or acknowledge others as described by Coggins and Carpenter (1978, in Miller, 1981, p. 118). A further justification for responding to the communication act by focusing attention on the object, rather than initiating interaction with the parent, could be that children may not be used to playing with their parents, either because their parents are not at home due to work commitments, or because adults tend not to play with their children as play is regarded as being undignified. (Reynolds, 1989). Furthermore,

few adults involve themselves in the play of children. Play is not seen as sacrosanct and sometimes it is regarded with suspicion and as a waste of time. Adults do not seek to direct play (Reynolds, 1989, p. 87).

It is also interesting to note that most of the objects used in this sample were not familiar to the children, except possibly the telephone, yet children responded appropriately to them. This is particularly relevant with objects that are not common in the homes, such as pens and paper as this has implications for school.

\section{General Discussion}

In this study, some attempt was made to relate the subjects language to research performed on English speaking peers in order to investigate the possibility of common trends. Attempts were also made to observe parallel trends in subjects whose language more closely resembles Zulu, such as Hebrew. There has been no report of these in the study as Berman (1985, p. 267 ) has claimed that most of the developmental data obtained for Hebrew "are biased in favour of the language of $2-3$ year olds" and thus no trends could be observed.

Repertoire of assessment procedures. A comprehensive test battery, including parent report, mother-child and testerchild interaction was utilised in order to obtain these results. All measures were useful and complemented each other, for example, tester-child interaction was not found to be effective for eliciting expressive language, eg., naming body parts, yet this interaction provided worthwhile results for pragmatic, eg., trying to weigh up a toy, and receptive, eg., identifying body parts, language abilities. However, when correlating these interactions statistically, poor results were obtained indicating the need for such a comprehensive assessment at this stage of language development.

Nonetheless, although this test battery is believed to be extensive, it does not appear to be practical, as administration is time consuming and restricting in terms of requiring specialised and sophisticated equipment such as video cameras and specialist knowledge of language assessment and analysis. The results of this study, although indicating that all measures are useful, also indicate that parent report provides a general evaluation of all parameters of child language. Thus, it is recommended that parent report be used as a screening tool for children of this age, as this is cost effective; a valuable basis for a rapid evaluation of child language and a useful measurement over a wide range of social class (Dale, Bates, Resnick \& Morriset, 1989; Dale, 1991). Parent reports are effectively used in appraisal at this stage of language development, for example, the Receptive-Expressive Emergent Language Scale (BzochLeague, 1979). In addition, parent reports are particularly suitable for the South African situation and for Zulu-speakers specifically, because they have limited access to formal intervention facilities for speech, language and hearing disorders. Parent reports can easily be utilised in the community by primary health care workers. The results of this study provide information about relevant content to include in such screen- ing assessments. (See Appendix B).

The findings of this study have epidemiological implications on both a primary and secondary level of prevention. On a primary level, it is now possible to begin to educate people, particularly mothers and caregivers, about how to stimulate language at this level in order to prevent language problems from occurring. On a secondary level, this study has established preliminary norms for 18-month-old Zulu speakers which were previously nonexistent. Further research is required for validation and to establish more norms than these early findings so that speech, language and hearing therapists will be able to compare other children to these subjects in order to identify delayed or disordered language. Once these norms have been established, mass screening of all Zulu speaking children, of this age, can be undertaken in order to determine the prevalence and incidence of communication disorders. ( $M$. Marge, personal communication, April 20, 1992). Such early identification would prevent the serious and long term consequences of language disorders that affect the psychological, educational and vocational dimensions of the child (Bernstein \& Tiegerman, 1989; Penn \& Segal, 1982, and Aram \& Nation, 1980).

\section{CONCLUSION}

The language abilities of these 18-month-old Zulu speakers indicated that the development of the content, form and use of language are all integrated and that communication precedes and facilitates speech and language behaviour (Lahey, 1988; Bernstein \& Tiegerman, 1989). On a receptive level, subjects were able to understand two-part instructions, identify body parts and three objects. Expressively, subjects were at the early one word linguistic stage, having a lexicon of 4,12 words and an MLU of 0,65 , with a mean number of morphemes of 2,78 and a mean number of utterances per turn of 1,519 . Tester-child interaction provided few results as $85 \%$ of sub jects could not name simple objects or body parts. Pragmatically, the subjects responded mostly nonverbally, by focusing attention on an object rather than communicating verbally with the adult to items presented in communicative acts. This demonstrates the link between pragmatic and expressive language abilities and is to be expected in view of the limited expressive abilities. This analysis also contributed examples of pragmatic behaviour that were specific to Zulu culture, such as mothers tying a doll to their childrens' backs and the thanking ritual.

As regards the second aim of this study, to evaluate the effectiveness of assessment materials, the previous discussion indicated that parent report provided a comprehensive method of assessing young children's language. In addition, this method is thought to be particularly suitable and useful for the South African situation, both in terms of the broad range of information it provides and in terms of being accessible to administration by a wide range of health personnel. This study has also established preliminary norms for 18 -monthold Zulu speakers which should be used to establish comprehensive norms to determine the prevalence and incidence of communication disorders in the Zulu speaking population. As the year 2000 rapidly approaches, it is necessary that speech, language and hearing therapists make a concerted effort to undertake research of this nature such as incidence and prevalence studies, in order to provide an effective service to all people with communication problems in South Africa.

\section{ACKNOWLEDGEMENTS}

The author acknowledges with appreciation a grant from the HSRC, which funded this research. Ursula Booysen of the 
Institute of Biostatistics of the Medical Reseach Council is sincerely thanked for her assistance and patience with the statistical data. Furthermore, the immense contribution of Bennedicta Tlhomola, Sylvia Jongidiza, Sydwell Khene, Bernice Mdongoana and Tebogo Rankoane is acknowledged for their invaluable contribution in data collection and analysis.

\section{REFERENCES}

Aram, D.M., \& Nation, J.E. (1980). Preschool language disorders and subsequent language and academic difficulties. Journal of Communication Disorders, 13, 159-170.

Ballantine, J., Ballantine, P.R. \& Morgan, R. (1982, July). Auditory perceptual skills in Zulu school children - A preliminary normative investigation. SASHA Newsletter, 196, 5-20.

Bates, E., Bretherton, I., \& Snyder, L. (1988). From first uords to gram mar: Individual differences and dissociable mechanisms. Cambridge: Cambridge University Press.

Bates, E., Camaioni, L., \& Volterra, V. (1979). The acquisition of per formatives prior to speech. In E. Ochs, \& B. B. Schieffelin (Eds.) Developmental pragmatic. (pp.111-130). New York: Academic Press.

Berman, R.A. (1985). The acquisition of Hebrew. In D. I. Slobin (Ed.), The crossinguistic study of language acquisition Vol. 1: The data (pp.255-371). Hillsdale, New Jersey: Lawrence Erlbaum Associates.

Bernstein, D.K., \& Tiegerman, E. (1989). Language and communication disorders in children (2nd ed.). Columbus, $\mathrm{OH}$ : Charles $\mathrm{E}$. Merrill.

Bhatnager, S., \& Whitaker, H.A. (1984). Agrammatism on inflectional bound morphemes: A case history of a Hindi speaking aphasic patient. Cortex, 20, $295-301$.

Bzoch, K.R., \& League, R. (1979). Receptive-Expressive Emergent Language Scale for the measurement of language skills in infancy.

Chapman, R.S. (1981). Exploring children's communicative intents. In J.F. Miller (Ed.), Assessing language production in children: Experimental procedures. (pp. 111- 138). Baltimore: University Park Press.

Child, D.R., \& Johnson, M.S. (1991). Preventable and nonpreventable causes of voice disorders. Seminars in Speech and Language, 12(1), $1-13$.

Clark, E.V. (1979). Building a vocabulary: Words for objects, actions and relations. In P. Fletcher \& M. Garman (Eds.), Language acquisition: Studies in first language development (pp. 149-160). Cambridge: Cambridge University Press.

Cohen, L., \& Manion, L. (1991). Research methods in education (3rd ed.). London: Routledge.

Conti-Ramsden, G., \& Dykins, J.'(1991). Mother-child interactions with language-impaired children and their siblings. British.Journal of Disorders of Communication! 26, 337-354.

Dale, P.S. (1991). The validity of a parent report measure of vocabulary and syntax at 24 months. Journal of Speech and Hearing Research, 34, 565-571.

Dale, P.S., Bates, E., Reznick, J.S., \& Morisset, C. (1989). The validity of a parent report instrument of child language at 20 months. Journal of Child Language, 16, 239-249.

Drew, M. (1982, September/October). Editorial. SASHA Neusletter, 250, 1-6.

Doke, C.M. (1945). Textbook of Zulu grammar (4th ed.). London: Longmans, Green and $\mathrm{Co}$

Fromkin, V. \& Rodman, R. (1978). An introduction to language (2nd ed.). New York: Holt, Reinehart and Winston.

Gerber, S. (1990). Prevention: The etiology of communicative disorders in children. Englewood Cliffs NJ: Prentice Hall.

Gesell, A. (Ed.). (1954). The first five years of life. A guide to the study of the preschool child. London: Metheun.

Gowlett, D.F.(1975, November). Toward Black-White understanding in South Africa. Lecture delivered to The Institute for the Study of Man in Africa Johannesburg.

Hedrick, D.L., Prather, E. M., \& Tobin, A. R. (1984). Sequenced inventory of communication development. Test Manual. (rev. ed.). Seattle: University of Washington Press.

Address correspondence to Ms M. Bortz, Department of Speech Pathology and Audiology, University of the Witwatersrand, Private Bag 3, Wits 2050.
Holt, K.S. (1977). Developmental paediatrics: Perspectives and practice. London: Butterworths.

Hopper, R., \& Naremore, R.J. (1978). Children's speech: A practical introduction to communication development (2nd ed.). New York: Harper and Row.

Illingworth, R. S. (1983). The normal Child. Some problems of the early years and their treatment (8th ed.). Edinburgh: Churchill Livingstone.

Lahey, M. (1988). Language disorders and language development. New York: Macmillan.

Marge, M. (1991). Introduction to the prevention and epidemiology of voice disorders. Seminars in Speech and Language, 12(1), 49-73.

McReynolds, L.R., \& Kearns, K. P. (1983). Single subject experimental designs in communicative disorders. Baltimore: University Park Press.

McTear, M.F. \& Conti-Ramsden, G. (1992). Pragmatic disability in children. London: Whurr.

Miller, B. J., \& Keane, C.B. (1983). Encyclopedia and dictionary of medicine, nursing and allied health. (3rd ed.). Philadelphia: W.B. Saunders.

Miller, J.F. (1981). Assessing language production in children: Experimental procedures. Baltimore: University Park Press.

Nicolosi, L., \& Collins. (1989). Developmental sequences of language behaviour: Overview. In L. Nicolosi, E. Harryman, \& J. Kresheck (1989). Terminology of communication disorders, speech-languagehearing. ( 3 rd ed.). Baltimore: Williams \& Wilkins.

Nicolosi, L., Hartyman, E. \& Kresheck, J. (1989). Terminology of communication disorders, speech-language- hearing. (3rd ed.). Baltimore: Williams \& Wilkins.

Ochs, E., \& Schieffelin, B.B. (Eds.). (1979). Developmental pragmatics. (p.110). New York: Academic Press.

Oxford Reference Concise Medical Dictionary. (1990). (3rded.). Oxford: Oxford University Press.

Penn, C. \& Segal, D. (1982). Case history factors in a group of languageimpaired children. The South African Journal of Communicarion Disorders, $29,3-14$

Peterson, D.R., \& Thomas, D.B. (1978). Fundamentals of epidemiology. Lexington, MA: D.C. Heath and Company.

Read, M. (1959). Children and their fathers: Growing up among the Ngoni of Nyasaland. Fackenham: Metheun.

Reynell, J. (1978). Reynell Developmental Language Scales, (rev. ed). London: National Foundation for Educational Research.

Reynolds, P. (1989). Childhood in Crossroads: Cognition and society in South Africa. Claremont: David Phillip.

Roth, F. P., \& Spekman, N.J. (1984). Assessing the pragmatic abilities of children: Part 2. Guidelines, considerations, and specific evaluation procedures.Journal of Speech and Hearing Disorders, 49, 12-17.

Segal, D. (1982, November/December). Community-based therapy: Some preliminary suggestions. SASHA Newsletter, 251, 15-18.

Suzman, S.M. (1990). Language acquisition in Zulu. Unpublished Doctoral Dissertation. University of the Witwatersrand, Johannesburg.

Thoman, E.B. (1981). Affective communication as the prelude and context for language learning. In R.L. Schiefelbusch, \& D.D. Bricker (Eds.), Early language: Acquisition and intervention (pp. 181200). Baltimore: University Park Press.

Van Riper, C., \& Emerick, L. (1990). Speech correction: An introduction to speech pathology and audiology (8th ed.). Englewood Cliffs, NJ: Prentice Hall.

Vorster, J. (1980). Manual for the Test for Oral Language Production. Pretoria: S.A. Institute for Psychological and Psychometric Research, H.S.R.C.

Westby, C. E. (1980). Assessment of cognitive and language abilites through play. Language, Speech and Hearing Services in Schools, XI, 151-168.

Wetherby, A.M., \& Prutting, C. (1984). Profiles of communicative abilities. Journal of Speech and Hearing Research, 27, 364-377.

Wetherby, A.M., Yonclas, D.G., \& Bryan, A.A. (1989). Communicative profiles of preschool children with handicaps: Implications for early identification. Journal of Speech and Hearing Disorders, 54, $148-158$. 


\section{APPENDIX A}

\section{Questions used in the parent report}

[INSTRUCTION: ASK THE MOTHER OR CAREGIVER THESE QUESTIONS THE FIRST TIME THEY COME TO WITS.]

1) Can your child say any words? Yes/No. If yes, elaborate on the words.

2) Does your child understand what you say to her/him? Yes/ No. If yes:

a) Provide examples of what your child understands.

b) Provide examples of words you say that your child understands.

3) Does it sound as if your child speaks to her/himself? Yes/ No. If yes, what does your child say?

[It should sound like they are speaking to themselves, but there may be no real speech, just the rhythm and intonation of speech. This is a clue or prompt that you can give to the mother if she doesn't understand the question.]

4) Does your child listen to you when you call her/him or speak to her/him? Yes/No. If yes, how do you know this?
5) Does your child copy what you say? Yes/No.

6) Does the child communicate when she/he wants something? Yes/No. If yes, how does your child communicate?

7) Does your child use her/his hands to communicate or point to what she/he wants? Yes/No.

8) Does the child sing? Yes/No.

9) Can your child understand and do simple instructions? Yes/No eg. Close the door, get the rag. If yes, what does your child understand, provide examples.

10) Can your child point to or show parts of her/his body?Yes/ No. If yes, which parts does your child know?

Based on Nicolosi \& Collins, (1989); Gesell (1954) and Hopper \& Naremore (1978).

\section{APPENDIX B}

\section{Receptive, Expressive and Pragmatic language abilities of 18-month-old Zulu speakers}

\section{Receptive Language}

- Listens and responds to communication addressed to him/ her

- Understands two-part instructions, for example hlalapantsi udle 'sit down and eat'

- Identifies a range of body parts

- Identifies three objects

\section{Expressive Language}

- Babbles and uses jargon

- Imitates and sings

- Four word vocabulary

- Inconsistent use of marked forms of noun classes

- MLU 0,65 words

- Difficulty naming objects in a formal test situation

\section{Pragmatic Language}

- Demonstrates autosymbolic play such as drinking from a cup, washing with a face cloth

- Uses common objects and toys appropriately for example pencil, paper, car and ball

- Imitates parents in domestic tasks, for instance sweeping with a broom

- Exhibits culture specific behaviours papate thanking ritual', carries doll tied to back

- Vocalises, to gain adult's attention

- Gestures to get adult's attention

- Simultaneously vocalises and gestures to achieve adult's attention

- Focuses attention on object, for example, attempts to blow up a balloon 